\title{
Electron spectroscopic investigation of polymers and glasses
}

\author{
Şefik Süzer \\ Department of Chemistry, Bilkent University, \\ 06533 Bilkent, Ankara, Turkey.
}

\begin{abstract}
X-ray induced photo and Auger electron spectroscopic techniques have been applied to investigate conducting polymers, their blends and some glasses. In the N1s region of the spectra of films containing polypyrrole the peak corresponding to $\mathrm{N}^{+}$at $402.0 \mathrm{eV}$ is separated from the neutral $\mathrm{N}$. Intensity of the $\mathrm{N}^{+}$peak can be correlated with electrical conductivity of the films and the spectroscopically derived ratio of $F / \mathrm{N}^{+}$ is close to 4 indicating that one $\mathrm{BF}_{4}^{-}$dopant ion is incorporated for every oxidized nitrogen center. In the spectra of the films of polythiophene and its blends peaks corresponding to $\mathrm{S}$ and $\mathrm{S}^{+}$can not be resolved, but again $\mathrm{F} / \mathrm{C}$ ratio correlates with the electrical conductivity. On the basis of measured XPS chemical shifts in the binding energies the chemical state of Sn $(+2$ or +4$)$ incorporated on to the float glasses could not be assigned. Use of the Auger parameter lets one separate relaxation and chemical contributions. The derived true chemical shifts of $\mathrm{Sn}$ on float-glasses are larger than those of $\mathrm{SnO}$ and/or $\mathrm{SnO}_{2}$ due to the larger ionic environment of the glass matrix.
\end{abstract}

\section{INTRODUCTION}

Over the last three decades electron spectroscopic techniques (both X-Ray Photoelectron Spectroscopy, XPS, and Auger Electron Spectroscopy, AES) have become one of the most important tools of chemist for any type of material characterization. Their surface sensitivity, applicability to any element (except for hydrogen), and capability to distinguish between various valence states through the chemical shifts are the most important assets of these techniques. Application of the electron spectroscopic techniques to electrically conducting polymeric materials in their unblended forms have been extensively reported [1-3]. Preparation of electroactive polymers with improved chemical and/or mechanical properties is still a scientifically and technologically important issue. Blending is one of the ways to achieve this goal. Blends of polypyrrole and polythiophene with polyamide has proved to be quite successful for some applications [4-6]. We have already reported an $x$-ray photoelectron spectroscopic investigation of polypyrrole and its blends with polyamide [7]. We have extended this study to polthiophene and its blends with polyamide.

Coating of Sn and its oxides have technological importance in applications like float-glass production, solar energy cells, protective and conductive coatings etc.. For many applications quantitative data of Sn, like surface coverage or depth profiling, are important parameters sought after. In some applications, however, further information like oxidation state, coordination number etc. are needed. XPS and/or AES studies attempting to distinguish between the two oxides of tin, $\mathrm{SnO}$ and $\mathrm{SnO}_{2}$, have found either absence or only a small difference in the core 
level binding energies [8-11]. In a different investigation it was demonstrated that although the core level shifts were not significant, XPS of the valence band region could unambiguously distinguish between the two oxides [12]. Another parameter which can de derived from the $x$-ray induced electron spectra is the Auger parameter, introduced by Wagner [13] and further developed by others $[14,15]$, can be very informative. In a recent study [16], we have reported the Auger parameters of the tin metal, tin oxides and chlorides. Here, we report our study to float glasses with different thickness and a tin oxide coated conducting glass. Tin is incorporated on to both surfaces of glasses produced by the float technique (float glasses). Incorporation of tin on to the tin-bath surface of the glass is through contact with liquid tin and is homogeneous while in the atmospheric surface it is known to be through precipitation of tin vapors and in forms of islands

\section{EXPERIMENTAL}

The electron spectrometer is a KRATOS ES300 with AlKa source. Quantitative data from the XPS data is obtained using the standard procedures [17].

Conducting polymer blend films were prepared by electrochemical polymerization of pyrrole or thiophene onto a polyamide dipcoated electrode at a constant predetermined potential. Electrochemical deposition of polypyrrole was carried out in a three compartment cell equipped with Pt foils $\left(1.0 \mathrm{~cm}^{2}\right.$ each) as working electrode (at $\left.+1.1 \mathrm{~V}\right)$ and counter electrodes. A capillary $(\mathrm{Ag} / \mathrm{Ag}+)$ was used as reference electrode and the solvent/electrolyte couple was acetonitrile/tetrabutylammonium tetrafluoroborate. For polythiophene working electrode was operated at $+2.0 \mathrm{~V}$. Electrochemical reduction was achieved by reversing the polarity and discharging the prepared films. X-ray photoelectron spectra of the various films were recorded after thorough washing with the solvent and drying the films while intact on their platinum electrodes.

Float glasses with thicknesses of 3, 4, 5, 6 and $10 \mathrm{~mm}$ were provided by the local producer (Türkiye Şişe-Cam A.S.) while the conducting tin oxide glass was a commercial tin oxide glass. Surface of the samples of appropriate size were wiped by a clean tissue paper before introduction into the spectrometer. Pressure in the analyzer chamber is kept below $5 \times 10^{-9}$ torr during analysis. Depth profiling was carried out using either (i) in-situ $\mathrm{Ar}^{+}$etching with $1 \mathrm{keV}$ ions or (ii) prior to introduction to the spectrometer with $2 \% \mathrm{HF}$ solution.

\section{RESULTS AND DISCUSSION}

\section{Conducting Polymers}

Fig. 1 displays parts of the photoelectron spectra of polypyrrole-only (PPy), polyamide/polypyrrole (PA/PPY), polythiophene (PTh) and polyamide/polythiophene blends in their conducting forms and after electrochemical reduction. (PA/PTh). Spectra of polyamide after electrochemical oxidation (PA(oxidized)) and further reduction (PA(ox.+red.)) are also included to ensure that electrochemical treatment does not introduce additional features. The strong features are due to F1s, $\mathrm{O} 1 \mathrm{~s}, \mathrm{~N} 1 \mathrm{~s}$ and C1s and S2s and 2p. Since our x-ray source is not monochromatized the F1s, C1s, S2s and S2p peaks are observed as single peaks at around 686, 285, 228 and $164 \mathrm{eV}$ respectively. The O1s peak around 532 is broad and can be deconvoluted into 2 or 3 components. The N1s peak in films containing polpyrrole has two components at 399.7 and $402.0 \mathrm{eV}$ which can be assigned to the neutral $(-\mathrm{N}-)$ and the quaternized nitrogens $\left(-\mathrm{N}^{+-}\right)$respectively. The relevant data are collected in Table 1. Examination of Figure 1 reveals that no additional features are introduced during electrochemical oxidation and/or reduction of the polyamide-only film. The N/C ratio determined from our result is not far from the stochiometric ratio given by the supplier $(0.05)$. Intensity of the 
extra peak observed at the high binding energy side, assigned to $\mathrm{N}^{+}$moieties, correlates with electrical conductivity of the films. The atomic ratio of $\mathrm{F}$ to $\mathrm{N}^{+}$derived from our XPS data is close to 4 for these films, indicating that one $\mathrm{BF}_{4}^{-}$dopant ion is introduced for every $\mathrm{N}^{+}$center. Both the $\mathrm{N}^{+}$and the $\mathrm{F} 1 \mathrm{~s}$ intensities decrease considerably after electrochemical reduction.

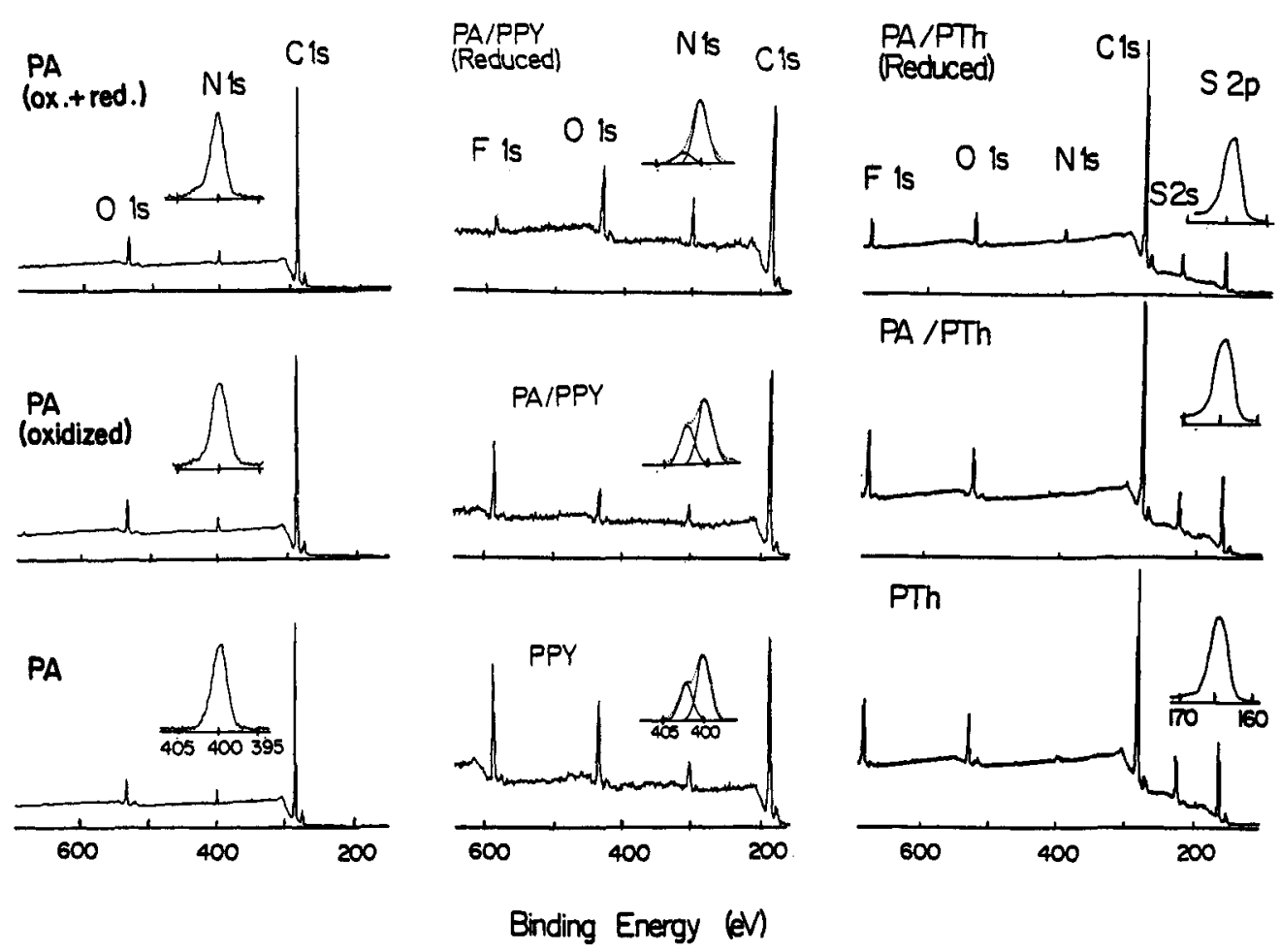

Fig.1. AlK $\alpha$ induced electron spectra of electrochemically prepared polypyrrole and polythiophene blended with polyamide. Spectra of the films after electrochemical oxidation and/or reduction are also included. Expanded N1s and S2p levels are also shown.

In the case of films of polythiophene, polyamide/polythiphene as prepared and after electrochemical reduction, our resolution does not permit to distinguish between the neutral $S$ and its oxidized form $\mathrm{S}^{+}$. Information about electrical conductivities of the films can still be derived from the atomic ratios of $\mathrm{F} / \mathrm{C}$. Again the $\mathrm{F} / \mathrm{C}$ ratio in films of polythiophene and its blend with polyamide are very close to each other and this ratio is smaller in the less conducting electrochemically reduced blend.

\section{Sn Coatings on Glasses}

Fig. 2 displays electron spectra (induced by AlK $\alpha$ x-rays) of a $3 \mathrm{~mm}$ float glass (bottom) and the tin oxide coated glass (top). Photoelectron lines corresponding to $\mathrm{O} 1 \mathrm{~s}, \mathrm{Cls}, \mathrm{Si} 2 \mathrm{~s}$ and $2 \mathrm{p}, \mathrm{Ca} 2 \mathrm{~s}$ and $2 \mathrm{p}$, $\mathrm{Sn} 4 \mathrm{~d}, 3 \mathrm{~d}$ and $3 \mathrm{p}$ lines as well as $\mathrm{O}, \mathrm{Na}$ and $\mathrm{Mg} \mathrm{KLL}$ and $\mathrm{Sn} \mathrm{MNN}$ (shown in the left side of the figure) Auger lines are the prominent features. Na KLL Auger and $\mathrm{Sn} 3 \mathrm{~d}_{3 / 2}$ lines overlap but can easily be separated by deconvolution. Intensity of Sn lines vary depending on the surface examined (i.e. tin-bath or atmospheric), the thickness of the glass and naturally the etching time. The relevant data are collected in Table 2. The table also contains data on $\mathrm{SnO}, \mathrm{SnO}_{2}$ as well as the tin-oxide conducting glass. 
TABLE 1. XPS data of electrochemically prepared polypyrrole and polythiophene together with their blends with polyamide.

\begin{tabular}{|c|c|c|c|c|c|c|c|c|}
\hline \multirow{2}{*}{\multicolumn{2}{|c|}{ 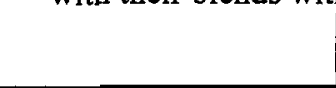 }} & \multirow{2}{*}{\multicolumn{4}{|c|}{ Binding Energy $(\mathrm{eV})$ (Atomic Percentage) }} & \multirow{2}{*}{\multicolumn{2}{|c|}{ At. Ratio }} & \multirow[b]{3}{*}{$\begin{array}{l}\text { Cond. } \\
(\mathrm{S} / \mathrm{cm})\end{array}$} \\
\hline & & & & & & & & \\
\hline & C1s & \begin{tabular}{c}
\multicolumn{2}{c}{$\mathrm{N} 1 \mathrm{~s}$} \\
$-\mathrm{N}_{-}-\mathrm{N}_{-}^{+}$
\end{tabular} & O1s & F1s & S2p & $\mathrm{F} / \mathrm{N}^{+}$ & $\mathrm{F} / \mathrm{C}$ & \\
\hline PA & $285.0(91)$ & $399.8(3) \quad-$ & $532.4(6)$ & - & - & - & - & - \\
\hline $\mathrm{PPy}$ & $285.0(65)$ & $399.7(5) \quad 402.0(3)$ & $532.3(14)$ & $686.3(13)$ & - & 4.4 & - & 2 \\
\hline PA/PPY & $285.0(74)$ & $399.7(5) \quad 401.8(3)$ & $532.3(7)$ & $686.3(11)$ & - & 3.6 & - & 2 \\
\hline $\begin{array}{l}\text { PA/PPY } \\
\text { (Red) }\end{array}$ & $285.0(71)$ & $399.7(10) 401.8(1)$ & $532.3(15)$ & $686.3(3)$ & - & 2.2 & - & 0.004 \\
\hline PTh & $285.0(68)$ & $400.5(2)$ & $532.8(10)$ & $686.5(7)$ & $164.5(14)$ & - & 0.10 & 4 \\
\hline PA/PTh & $285.0(69)$ & $400.6(1)$ & $532.9(9)$ & $686.7(7)$ & $164.6(14)$ & - & 0.10 & 3 \\
\hline $\begin{array}{l}\text { PA/PTh } \\
\text { (Red) }\end{array}$ & $285.0(74)$ & $400.8(3)$ & $532.8(9)$ & $686.8(4)$ & $164.7(10)$ & $\overline{-}$ & 0.05 & 0.008 \\
\hline
\end{tabular}

The measured binding energies of $\mathrm{SnO}, \mathrm{SnO}_{2}$ and $\mathrm{Sn}$ on glasses are very close to each other. On the basis of the raw binding energies of $\mathrm{Sn}$ one can not, unambiguously, decide on the chemical state of $\mathrm{Sn}$. The measured binding energies contain contributions from relaxation effects besides the chemical ones. At this point we must refer to the Auger parameter or the true chemical shift. As can be seen from the insert of Fig. 2, the $\mathrm{Sn}$ MNN Auger peaks of $\mathrm{SnO}_{2}$ and $\mathrm{SnO}$ exhibit a much larger (close to $1 \mathrm{eV}$ ) chemical shift. We can analyze the chemical shifts in binding energies, $\Delta \mathrm{E}_{\mathrm{ch}}$, using Wagner's approach of identifying compounds on the basis of their Auger parameters:

$$
\alpha=E_{b}+E_{k}
$$

Where $E_{b}$ is the binding energy of the photoelectron and $E_{k}$ is the kinetic energy of the Auger electron emitted as a result of Auger process involving the same electron level. The Auger parameter exhibits a much larger shift in various $\mathrm{Sn}$ coatings and depends linearly on $\mathrm{Sn} / \mathrm{Si}$ ratio (as plotted in the right hand side of Fig. 2). The shift in $E_{b}$ can be regarded as the sum of (i) the chemical shift, $\Delta \mathrm{E}_{\mathrm{ch}}$, which depends on the effective charge of the atom, (ii) the relaxation energy. The latter consists of two components, intra and extra atomic relaxations, $E_{i r}$ and $E_{\text {er }}$ determined by the interaction of other electrons within the same atom or the neighboring ones. One can roughly describe them as gas phase (intra-atomic) and solid-state (extra-atomic) contributions. Regarding $\mathrm{E}_{\mathrm{ir}}$ constant one obtains the binding energy shift with respect to zero-valent bulk material (Sn metal): $\quad \Delta \mathrm{E}_{\mathrm{b}}=\Delta \mathrm{E}_{\mathrm{ch}}+\Delta \mathrm{E}_{\mathrm{er}}$

TABLE 2. XPS/XAES Data of some float glasses, the tin oxide conducting glass together with

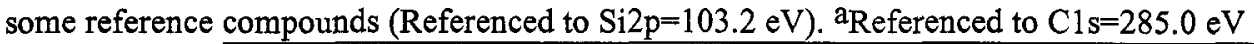

\begin{tabular}{|c|c|c|c|c|c|c|c|}
\hline & \multirow{2}{*}{$\begin{array}{l}\mathrm{BE}(\mathrm{eV}) \\
\mathrm{Sn}_{3} \mathrm{~d}_{5 / 2}\end{array}$} & \multirow{2}{*}{$\begin{array}{l}\mathrm{KE}(\mathrm{eV}) \\
\mathrm{Sn}_{\mathrm{MNN}}\end{array}$} & \multirow{2}{*}{$\begin{array}{l}\alpha_{\mathrm{Sn}} \\
(\mathrm{eV})\end{array}$} & \multirow{2}{*}{$\begin{array}{l}\Delta \mathrm{E}_{\mathrm{er}} \\
(\mathrm{eV})\end{array}$} & \multirow{2}{*}{$\begin{array}{l}\Delta \mathrm{E}_{\mathrm{ch}} \\
(\mathrm{eV})\end{array}$} & \multicolumn{2}{|c|}{ Atomic Ratio } \\
\hline & & & & & & $\mathrm{Sn} / \mathrm{Si}$ & $\mathrm{O} / \mathrm{Si}$ \\
\hline $3 \mathrm{~mm}$ & 488.2 & 430.4 & 918.7 & -1.8 & 0.8 & 0.283 & 4.12 \\
\hline $3 \mathrm{~mm}$ (surf.) & 487.7 & 430.6 & 918.3 & -2.0 & 0.1 & 0.026 & 3.12 \\
\hline $4 \mathrm{~mm}$ & 488.1 & 430.7 & 918.8 & -1.8 & 0.7 & 0.235 & 3.12 \\
\hline $5 \mathrm{~mm}$ & 488.0 & 430.5 & 918.5 & -1.9 & 0.5 & 0.193 & 4.68 \\
\hline $6 \mathrm{~mm}$ & 488.1 & 430.2 & 918.3 & -2.0 & 0.5 & 0.164 & 3.93 \\
\hline $10 \mathrm{~mm}$ & 488.1 & 430.5 & 918.6 & -1.8 & 0.7 & 0.222 & 3.22 \\
\hline Cond. Glass ${ }^{\mathrm{a}}$ & 487.6 & 431.9 & 919.5 & -1.4 & 0.6 & - & 2.58 \\
\hline $\mathrm{Sn}^{\mathrm{a}}$ & 485.6 & 436.7 & 922.3 & - & - & - & - \\
\hline $\mathrm{SnO}^{\mathrm{a}}$ & 487.1 & 432.5 & 919.6 & -1.3 & 0.2 & - & 0.98 \\
\hline $\mathrm{SnO}_{2}{ }^{\mathrm{a}}$ & 487.5 & 431.7 & 919.1 & -1.6 & 0.3 & - & 1.66 \\
\hline
\end{tabular}


As can be seen from the table the chemical shift computed using this procedure is $0.15 \mathrm{eV}$ for $\mathrm{SnO}$ and $0.35 \mathrm{eV}$ for $\mathrm{SnO}_{2}$. For $\mathrm{Sn}$ coated on glasses, however, the derived shifts vary between 0.5 and 0.8 and are larger than that of $\mathrm{SnO}_{2}$. This can be rationalized if one considers that $\mathrm{Sn}$ atoms in the glass matrix are in stronger ionic environment compared to the oxides.

Contributions to the chemical and relaxation terms of the Auger electrons could be expressed as follows : $\Delta E_{k}=-\Delta E_{c h}+3 \Delta E_{e r}, \Delta \alpha=-\Delta E_{b}+\Delta E_{k}, \Delta \alpha=2 \Delta E_{e r}$

This procedure lets one separate chemical (the true chemical shift) and relaxation contributions from the measured binding energies and Auger parameters.

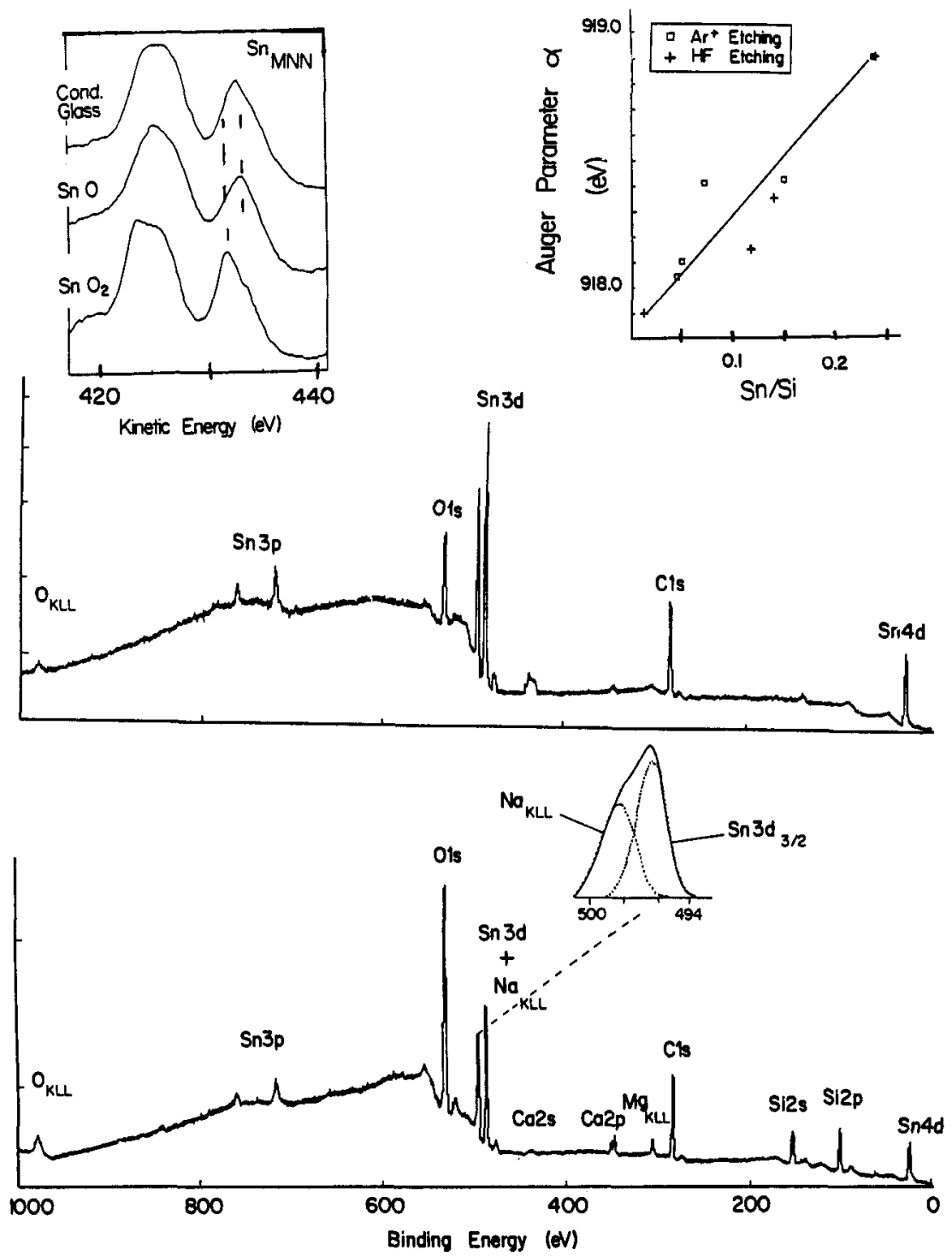

Fig.2. AlK $\alpha \mathrm{x}$-ray induced electron spectra of $3 \mathrm{~mm}$ float glass (bottom), the tin oxide coated conducting glass (middle). Th $\mathrm{Sn} \mathrm{MNN}$ Auger pekas of $\mathrm{SnO}, \mathrm{SnO} 2$ and the conducting glass are shown as an insert in the left hand-side and change of the Auger parameter as a function of $\mathrm{Sn} / \mathrm{Si}$ ratio in various float-glasses are shown on the right hand-side.

This work is supported by TÜBITAK, The Scientific and Technical Research Council of Turkey, through the project TBAG-Ü-15/7. 


\section{REFERENCES}

1. E.T. Kang, K.G. Neoh and K.L. Tan, $A d v$.Polm.Sci. 106, 135 (1993).

2. P. Pfluger and G.B. Street, J.Chem.Phys. 80, 544 (1984).

3. W.R. Salaneck WR, Rep.Prog.Phys. 54,1215 (1991).

4. H.L. Wang, L. Toppare and J.E. Fernandez, Macromolecules 23, 1053 (1987).

5. F. Selampınar, U. Akbulut, T. Yalçın, Ş. Süzer and L. Toppare, Synth.Met. 62, 201 (1994).

6. M. Randazzo, L. Toppare and J.E. Fernandez (1994) Macromolecules 27, 5102 (1994).

7. Ş. Süzer, L. Toppare, G.C. Allen and K.R. Hallam, J.Molec.Struc. 349, 243 (1995).

8. W.E. Morgan and J.R. Van Wazer, J.Phys.Chem. 77, 964 (1973).

9. C:T. Lau and G.K. Wertheim, J.Vac.Sci.Technol, 15:622 (1978).

10. R.G. Edgell, S. Eriksen and W.R. Flavell, Solid State Com. 60, 835 (1986).

11. J. Luo, C. Xu, J.Non.Cryst.Solids 119, 37 (1990).

12. J.M. Themlin, M. Chtaib, L. Henrard, P. Lambin, J. Darville and J.M. Gilles, Phys.Rev.B 46, 11914 (1992).

13. C.D. Wagner, L.H. Gale and R.H. Raymond, Anal.Chem. 51, 466 (1979).

14. T.D. Thomas and P. Weightman P, Phys.Rev.B 33, 5406 (1986).

15. G. Moretti and P.Porta, Surf.Interface Anal. 20, 675 (1993).

16. T. Voscoboinikov and Ș. Süzer, Submitted to J.Phys.Chem (1995).

17. J. Chastain, Hanbook of X-Ray Photoelectron Spectroscopy, Perkin-Elmer Co (1992).

18. L. Colombin, H. Charlier, A. Jelli, G. Debras and J. Verbist, J.Non.Cryst.Solids 38, 551 (1980). 